ISSN 0719-7160

\title{
RELIGIONES INDÍGENAS Y JURISPRUDENCIA CHILENA
}

\author{
RODRIGO CÉSPEDES PROTO
}

\begin{abstract}
Resumen
Este trabajo analiza los casos judiciales chilenos que han lidiado, en el ámbito criminal y ambiental, con aspectos relacionados con creencias y prácticas ancestrales indígenas. Los fallos aplican tratados como el Pacto Internacional de Derechos Civiles y Políticos (1966) y la Convención OIT-169 (1989). Estas decisiones tienen relevancia para la dogmática penal en materia de eximentes de responsabilidad criminal y también para la estructura del procedimiento de evaluación impacto ambiental.
\end{abstract}

Palabras Clave:

\begin{abstract}
This article examines relevant Chilean case-law which has dealt with indigenous religious beliefs and practices, both in criminal and environmental law. The judgments analyzed in this work have domestically applied treaties, such as the ICCPR (1966) and the ILO-Convention 169 (1989). These judicial decisions are important on the matter of cultural defenses and to the structure of the Chilean environmental impact assessment procedure.
\end{abstract}

Keywords:

DOI: $10.7764 /$ RLDR.6.72

\section{Introducción: Religiones indígenas o étnicas}

El concepto de religión es bastante extenso e incluye muchas cosmovisiones diferentes. El Comité de Derechos Humanos de la ONU ha declarado que el Artículo 181 del Pacto Internacional de Derechos Civiles y Políticos protege ampliamente e incluye "abarca la libertad de pensamiento sobre todas las cuestiones, las convicciones personales y el compromiso con la religión o las creencias, ya se manifiesten a título individual o en comunidad con otras personas. El Artículo 18 protege las creencias teístas, no teístas y ateas, así como el derecho a no profesar ninguna religión o creencia. Los términos 'creencias' y 'religión' deben entenderse en sentido amplio. El Artículo 18 no se limita en su aplicación a las religiones tradicionales o a las creencias con características o prácticas institucionales análogas a las de las religiones tradicionales. Por eso, el Comité ve con preocupación cualquier tendencia a discriminar contra cualquier religión o creencia, en particular

\footnotetext{
${ }^{1}$ Artículo 18: 1. Toda persona tiene derecho a la libertad de pensamiento, de conciencia y de religión; este derecho incluye la libertad de tener o de adoptar la religión o las creencias de su elección, así como la libertad de manifestar su religión o sus creencias, individual o colectivamente, tanto en público como en privado, mediante el culto, la celebración de los ritos, las prácticas y la enseñanza. 2. Nadie será objeto de medidas coercitivas que puedan menoscabar su libertad de tener o de adoptar la religión o las creencias de su elección. 3. La libertad de manifestar la propia religión o las propias creencias estará sujeta únicamente a las limitaciones prescritas por la ley que sean necesarias para proteger la seguridad, el orden, la salud o la moral públicos, o los derechos y libertades fundamentales de los demás. 4. Los Estados Partes en el presente Pacto se comprometen a respetar la libertad de los padres y, en su caso, de los tutores legales, para garantizar que los hijos reciban la educación religiosa y moral que esté de acuerdo con sus propias convicciones.
} 
las más recientemente establecidas, o las que representan a minorías religiosas que puedan ser objeto de la hostilidad por parte de una comunidad religiosa predominante." ${ }^{2}$ En términos simples, 'creencia' es un concepto amplio que incluye, convicciones religiosas y no-religiosas.

Por cierto, dentro de esta definición se encuentran incluidas las religiones indígenas. Éstas son las originarias de un lugar que fueron desplazadas por los colonizadores como paganismo, superstición y, consecuencial e inicialmente, marginalizadas y demonizadas por la religión de los conquistadores. $^{3}$ Si bien en todo país civilizado existe libertad religiosa, aún se discrimina este tipo de creencias como el sacrificio ritual de animales, ${ }^{4}$ el consumo ceremonial de drogas ${ }^{5}$ o la caza de animales protegidos. ${ }^{6}$ Las fuentes de protección internacional más importantes son el Artículo 27 del Pacto Internacional de Derechos Civiles y Políticos, ${ }^{7}$ y los Artículos $5(a)^{8}$ y $8^{9}$ de la Convención

\footnotetext{
2 Observación General No. 22, Comentarios generales adoptados por el Comité de los Derechos Humanos, Artículo 18 - Libertad de pensamiento, de conciencia y de religión, 48o período de sesiones, U.N. Doc. HRI/GEN/1/Rev.7 at 179 (1993), paras.1-2.

3 TAFJORD, Bjørn Ola, "Indigenous religion (s) as an analytical category", Method \& Theory in the Study of Religion (2013) Vol. 25 Nr. 3, pp 221-243.

${ }^{4}$ Por ejemplo, Church of the Lukumi Babalu Aye, Inc. v Hialeah, 508 US 520 (1993). En este caso, una comunidad practicaba la Santería, creencia en que el sacrificio de animales es parte esencial de sus rituales. Inmediatamente antes de establecerse, la Municipalidad promulgó una ordenanza que prohibía el sacrificio de animales "que no tuviera el fin primario de proporcionar alimento" (se excluía el kosher, la casa deportiva y la eutanasia, entre otros). La Corte Suprema Americana estimó inconstitucional la regulación. Se estimó que las prácticas religiosas no tienen que parecer como racionales para la mayoría y que la regulación estaba específicamente diseñada para prohibir una práctica religiosa determinada. Esa aproximación no es universal, por ejemplo, en Jewish Liturgical Association Cha'are Shalom Ve Tsedek v France (2000), App. 27417/95, la Corte Europea de Derechos Humanos consideró legítima la prohibición de celebrar el ritual kosher por privados no autorizados a actuar como carniceros. La Corte Constitucional Federal Alemana, en sentencia 1 BvR 1783/99 de 01/15/2002, a instancia de Musulmanes conservadores, declaró inconstitucional la prohibición del sacrificio animal considerando que el contacto con sacrificio es parte importante del halal.

${ }^{5}$ En Employment Division, Department of Human Resources of Oregon v Smith (1990), 494 US 872, la Corte Suprema Americana declaró constitucional negar beneficios de desempleo a un trabajador despedido por consumir peyote, droga ilegal, como parte de un ritual religioso de la Iglesia de los Nuevos Nativos Americanos. Hay dos votos de minoría. La American Indian Religious Freedom Act sólo excepciona a los nativos americanos de esta prohibición. Siguiendo la misma línea, la Corte Suprema Americana declaró legitima la confiscación de hoasca, un té alucinógeno, en Gonzales, Attorney General of the United States and ors v O Centro Espirita Beneficente União do Vegetal (2006), Docket No 04-1084, 546 US 418 (US), 126 S.Ct. 1211 (2006), 163 L.Ed. 2d 1017 (2006), 74 USLW 4119 (2006). En Sud África, la prohibición del uso ritual de cannabis fue sostenida por su Corte Constitucional en Prince $v$ President of the Law Society of the Cape of Good Hope and ors., Case CCT 36/00.

${ }^{6}$ La Corte Suprema Mexicana sostiene que deben tomarse en cuenta las costumbres indígenas en un delito contra el ambiente (posesión de huevos de tortuga, una especie protegida), Amparo Directo en Revisión 1624/2008.

${ }^{7}$ Artículo 27: En los Estados en que existan minorías étnicas, religiosas o lingüísticas, no se negará a las personas que pertenezcan a dichas minorías el derecho que les corresponde, en común con los demás miembros de su grupo, a tener su propia vida cultural, a profesar y practicar su propia religión y a emplear su propio idioma.

${ }^{8}$ Artículo 5: Al aplicar las disposiciones del presente Convenio: (a) deberán reconocerse y protegerse los valores y prácticas sociales, culturales, religiosos y espirituales propios de dichos pueblos y deberá tomarse debidamente en consideración la índole de los problemas que se les plantean tanto colectiva como individualmente.

9 Artículo 8: 1. Al aplicar la legislación nacional a los pueblos interesados deberán tomarse debidamente en consideración sus costumbres o su derecho consuetudinario. 2. Dichos pueblos deberán tener el derecho de conservar sus costumbres e instituciones propias, siempre que éstas no sean incompatibles con los derechos fundamentales definidos por el sistema jurídico nacional ni con los derechos humanos internacionalmente reconocidos. Siempre que sea necesario, deberán establecerse procedimientos para solucionar los conflictos que
} 
ISSN 0719-7160

OIT-169. Es decir, gozan de la protección de los derechos de las minorías y de los indígenas. La distinción es importante porque algunos países no han ratificado el tratado OIT 169 (por ejemplo, Canadá, EE.UU., Suecia, Noruega, Finlandia, Rusia, Australia, Nueva Zelanda ${ }^{10}$ a diferencia de la Convención de Derechos Económicos, Sociales y Culturales que está más ampliamente extendida. Estas religiones se han revalorizado por el Movimiento Indigenista, ${ }^{11}$ una reciente corriente cultural y política que cuestiona los mecanismos de discriminación y el etnocentrismo de la cultura dominante en perjuicio de los pueblos originarios, normalmente en minoría, poniendo énfasis en el pluralismo. Los movimientos que adhieren a esta ideología están presentes en todo el mundo, pero con mayor fuerza (por razones obvias) en Latinoamérica. Este tipo de ideologías se han plasmado en nuevas constituciones como la de Bolivia (2009). En menor medida, la sensibilidad por los temas indígenas ha influido en Chile, con la aprobación de legislación sobre indígenas (Ley 19.253) y la ratificación del Convenio-OIT 169 en 2008. Indudablemente, como veremos, esta tendencia ha influido en la jurisprudencia chilena.

\section{Los casos chilenos}

La jurisprudencia chilena ha fallado, de forma relativamente significativa, asuntos relacionados con religiones indígenas en dos tipos de materias. Los primeros son asuntos concernientes al tráfico de drogas por transporte de hojas de coca utilizadas en un ritual religioso por los aimaras. Los segundos tienen que ver con sitios sagrados que fueron objetos de medidas administrativas o explotaciones susceptibles de ser controladas por el sistema de impacto ambiental.

\subsection{Los casos penales ${ }^{12}$}

Los casos penales fallados por la jurisprudencia chilena entran el en mundo de las "defensas culturales", ${ }^{13}$ un tipo de eximente de responsabilidad criminal (o atenuante) ya sea por falta de antijuridicidad (libre ejercicio de un derecho) o culpabilidad (ignorancia que genera un error de prohibición) que toma en cuenta las costumbre y especificidad cultural del imputado.

\footnotetext{
puedan surgir en la aplicación de este principio. 3. La aplicación de los párrafos 1 y 2 de este artículo no deberá impedir a los miembros de dichos pueblos ejercer los derechos reconocidos a todos los ciudadanos del país y asumir las obligaciones correspondientes.

10 Esto no quita que esos países hayan desarrollado una importante jurisprudencia sobre derechos indígenas, basada en su regulación doméstica y en tratados internacionales más generales, como el Pacto Internacional de Derechos Civiles y Políticos.

${ }^{11}$ FAVRE, Henri, Le mouvement indigéniste en Amérique latine, Editions L'Harmattan, Paris, 2009.

12 Ver CÉSPEDES, Rodrigo, "Indigenous Rights and Criminal Law in the Americas: Regional Application of the ILO Convention 169", en Chile and the Inter-American System of Human Rights (Karinna Fernández, Cristian Peña \& Sebastián Smart, Eds.), University of London, Institute of Latin American Studies, London, 2017, pp 157-170.

${ }^{13}$ Van BROECK, Jeroen, "Cultural defence and culturally motivated crimes (cultural offences)", European Journal of Crime, Criminal Law and Criminal Justice (2001) Vol. 9 No. 1, pp 1-32.
} 
Como señalábamos, los casos se relacionan con el trasporte a través de la frontera BolivianoChilena.

En el primer fallo, contra IWHC y LAHC (2007), ${ }^{14}$ los Tribunales resuelven utilizando el Artículo 27 de la Convención Internacional de Derechos Civiles y Políticos ${ }^{15}$ ya que aún la Convención OIT-169 no había sido ratificada por Chile. En este caso, dos mujeres aimaras de Bolivia fueron imputadas por posesión de hojas de coca (material esencial para la producción de cocaína). Una de las imputadas dijo a la policía que era un "encargo" para una amiga, que las utilizaría en ritual religioso. El Fiscal argumentó que la substancia era una droga según la Ley de Tráfico de Estupefacientes (2005) y, además el Artículo 54.1 $1^{16}$ de la Ley 19.253, según el cual se da cierto valor a la costumbre indígena, no se aplica porque las acusadas no eran chilenas. Las dos mujeres alegaron que si bien habían violado la letra de la ley, estaban exentas de responsabilidad porque sus tradiciones culturales indicaban que el comportamiento no era criminal. En su cultura, el uso de hojas de coca es común y habitual, lo que hace difícil entender y asumir la prohibición. El TOP de Calama ${ }^{17}$ absolvió a las dos mujeres ya que si bien incurrieron en el acto tipificado, no podían ser castigadas ya que no había intención criminal, ya que siguieron sus costumbres y prácticas religiosas (una especie de error de prohibición). La persona que iba a recibir el "encargo" declaró que las hojas de coca iban a ser usadas en una ceremonia religiosa. Sostuvo además que esas prácticas eran comunes y usuales en esa región ya que vivían muchos aimaras. El Fiscal impugnó la decisión argumentando que las imputadas confesaron incurrir voluntariamente en la conducta típica.

La Corte de Antofagasta desestimó la nulidad impetrada y confirmó la sentencia de primera instancia, absolviendo a las acusadas. En opinión de la Corte, el Artículo 27 de la Convención Internacional de Derechos Civiles y Políticos $^{18}$ reconoce a las minorías el derecho colectivo de mantener su cultura, usar su lengua y practicar su religión. ${ }^{19}$ Este Artículo es claro, no distingue y se aplica por igual a chilenos y extranjeros. ${ }^{20}$ Este Tratado, una vez ratificado, se encuentra incorporado el sistema jurídico chileno. Por lo tanto, no se les puede discriminar en base a su religión. Estas minorías pueden entonces practicar libremente su religión y cultura independientemente de su nacionalidad. ${ }^{21}$ Estas comunidades aimaras que viven en el altiplano chileno y boliviano usan las hojas de coca en su vida diaria y como parte de rituales ancestrales. ${ }^{22}$ El TOP simplemente aplicó adecuadamente una norma internacional vigente en el sistema

\footnotetext{
14 Rol 250-2007, Corte de Apelaciones de Antofagasta, confirma sentencia de primera instancia.

${ }^{15}$ Este artículo también ha sido usado en el extranjero para asuntos ambientales. Por ejemplo, Geological Survey of Finland and ors. v Ministry of Trade and Industry (1999), 31.3.1999/692 KHO:1999:14. Análisis en Oxford Reports on International Law in Domestic Courts C 930 (FI 1999). El Tribunal Supremo Administrativo Finlandés anuló la autorización dada a una minera que se otorgó sin estudiar el impacto en la caza de renos por los indígenas Sami.

16 "La costumbre hecha valer en juicio entre indígenas pertenecientes a una misma etnia, constituirá derecho, siempre que no sea incompatible con la Constitución Política de la República. En lo penal se la considerará cuando ello pudiere servir como antecedente para la aplicación de una eximente o atenuante de responsabilidad."

17 Sentencia del TOP de Calama, RUC 0600900213-6; RIT66/2007 (01/102007).

18 Ratificada por Chile el 23 de Marzo de 1976.

${ }^{19}$ Considerando 16.

${ }^{20}$ Considerando 17.

${ }^{21}$ Considerando 19.

${ }^{22}$ Considerando 21.
} 
chileno. ${ }^{23}$ Las hojas de coca son "droga" según la ley, pero en este caso, las fuentes incidentales del derecho penal, como la costumbre, tienen relevancia. En este caso, las hojas de coca no se usan como droga sino como parte de un ritual ancestral indígena. ${ }^{24}$

El fallo en cuestión tiene varios aspectos interesantes. Indudablemente es un ejemplo de la incorporación automática del derecho internacional a nuestro derecho doméstico en virtud del Artículo 5.2 de la Constitución, ${ }^{25}$ el que Chile está obligado a respetar. De acuerdo con el Comité de Derechos Humanos de la ONU, ${ }^{26}$ el Artículo 27 crea un derecho y correlativamente un deber estatal de asegurar la sobrevivencia de las manifestaciones religiosas y culturales de las minorías. Si bien la Corte no nombra el Artículo 18 de la misma Convención y su interpretación por el Comité, ${ }^{27}$ su aproximación es muy similar. De hecho, según el Comité el Artículo 18 protege creencias teístas, no-teístas y ateístas y no se limita a religiones tradicionales o con características institucionales. Por lo tanto, las religiones ancestrales indígenas están cubiertas por la Convención y deben ser tratadas en igualdad de condiciones y no discriminadas. De acuerdo con la Corte, las inculpadas ejercían un derecho al estar en posesión de hojas de coca destinadas a la práctica de un ritual religioso. La aplicación del Artículo 27, destinado a las minorías, resultaba apropiada ya que los aimaras son un grupo numéricamente inferior y no-dominante con particularidades étnicas, lingüísticas y religiosas que le dan una identidad propia. La conducta típica entonces se encuentra justificada para ese grupo étnico, pero no para el resto de la población. ${ }^{28}$

El segundo caso, Velázquez Zambrana (2015), ${ }^{29}$ es bastante similar al anterior. Durante un control aduanero de rutina, se encontraron varias mercancías no declaradas por un camionero boliviano. Entre éstas se incluían hojas de coca. En su versión, él la traía a una mujer aimara, quien a su vez quería venderla en una festividad religiosa. Si bien el inculpado reconoce que violó técnicamente la ley, pero sostiene que debería estar exento de responsabilidad criminal porque tradicionalmente los aimaras utilizan hojas de coca en determinados rituales y que su uso es masivo en Bolivia, donde no es ilegal.

En opinión de la Corte, el imputado no actuó con intención de traficar y no entendía la ilicitud de la conducta tipificada como delito. ${ }^{30}$ Según los Artículos 2, 5 y 8 de la Convención OIT169. Particularmente su Artículo 8(1) señala que al aplicar la ley debe tomarse en cuenta la costumbre indígena. Por lo tanto, su responsabilidad debe balancearse con sus particularidades sociales y culturales. ${ }^{31}$ Las hojas de coca son ampliamente usadas en Bolivia, donde no es ilegal,

\footnotetext{
${ }^{23}$ Considerando 20.

${ }^{24}$ Considerando 27.

${ }^{25}$ Ver FERNÁNDEZ GONZÁLEZ, Miguel Ángel, "La aplicación por los tribunales chilenos del derecho internacional de los derechos humanos", Estudios Constitucionales Año 8.1 (2010), pp 425-442.

26 Para.6.1, General Comment 23: The Rights of Minorities (Article 27) [UN Doc CCPR/C/21/Rev.1/Add.5, UN Doc HRI/GEN/1/Rev.6, 158, GAOR 49th Session Supp 40 vol 1, 107], Article 27 (Fiftieth session, 1994) ('General Comment $\left.23^{\prime}\right)$.

27 La Observación General 22 (1993) del Comité de Derecho de la ONU sobre libertad religiosa que reseñamos anteriormente.

28 TAMANAHA, Brian Z., 'Understanding legal pluralism: past to present, local to global', Sydney Law Review Vol. 30 (2008), pp 375-ss.

29 TOP de Arica, RUC No. 1410018700-1, RIT No. 27-2015.

${ }^{30}$ Considerando 16.

${ }^{31}$ Considerando 17.1.
} 
porque son vitales para la cultura aimara (se utilizan como medicina), por lo tanto su uso está protegido por la Convención OIT-169. ${ }^{32}$ Además, la salud como bien jurídico nunca estuvo en riesgo. ${ }^{33}$ La etnia aimara de Chile tiene que importarla porque el clima no permite cultivarla. ${ }^{34} \mathrm{Si}$ bien hay una prohibición general de importar y portar hojas de coca, en este caso hay una motivación cultural justificada. ${ }^{35}$

Este fallo también es un buen ejemplo de la penetración del derecho internacional en el sistema chileno. ${ }^{36}$ La Convención OIT-169 se ha aplicado más que nada a asuntos ambientales, pero además de este fallo, ha tenido alguna aplicación en el ámbito penal. ${ }^{37}$ En este caso, el Tribunal parece desplazar la eximente a la falta de culpabilidad y no a una causal de justificación.

\subsection{Casos ambientales}

La Ley 19.300 estableció un sistema de evaluación de impacto ambiental con una serie de etapas destinadas a prevenir daños al medio ambiente. La Convención OIT-169 complementó este procedimiento con un paso adicional, la consulta indígena (Artículos 6, 7.3 y 15.2), según lo ha reconocido la jurisprudencia. El Artículo 13.1 reconoce como principio la estrecha relación entre los indígenas y sus tierras ancestrales. La Ley 19.300 define recursos naturales como los componentes del medio ambiente susceptibles de ser utilizados por el ser humano para la satisfacción de sus necesidades o intereses espirituales, culturales, sociales y económicos. Su Reglamento entiende comprendido los monumentos nacionales, los sitios de valor antropológico, arqueológico, histórico y el patrimonio cultural en general. Dentro de los efectos adversos a considerar para entrar al sistema se encuentra alteración significativa "de los sistemas de vida y costumbres de grupos humanos". Se trata de una consecuencia en el medio ambiente bastante particular, más que una alteración del medioambiente, es una modificación sociocultural. Dentro de las áreas que pueden verse comprometidas se encuentran los territorios sagrados indígenas, como cementerios o lugares destinados a la realización de rituales.

Uno de esos casos es el de la Comunidad Indígena Chilcoco con Municipalidad de Arauco (2010). ${ }^{38}$ Después del Gran Terremoto del 2010, la Municipalidad comenzó a realizar trabajos de contención del Cerro Colo-Colo, un lugar sacro mapuche y además monumento histórico, para prevenir el posible colapso de algunas laderas. En esas labores, se destruyeron algunos árboles sagrados y restos arqueológicos. Las comunidades indígenas no fueron consultadas. Si bien la Municipalidad sostuvo que eran labores de emergencia no había tiempo para consultar 10 comunidades (con el riesgo de la falta de consenso), la Corte constata que había suficiente tiempo para consulta. El Tribunal resalta que no se juzga sobre la pertinencia de las medidas sino de compatibilizar el debido respeto a los símbolos indígenas y la seguridad de los habitantes (una suerte de test de proporcionalidad). En opinión de la Corte, la Municipalidad actuó

\footnotetext{
${ }^{32}$ Considerando 19.

${ }^{33}$ Cosiderando 20.

${ }^{34}$ Considerando 18.

${ }^{35}$ Considerando 23.1.

36 MILLÓN, Paula y CÉSPEDES, Rodrigo, "Derecho internacional de los derechos humanos y derecho doméstico chileno", Derecho Público Iberoamericano (2015) No. 7, pp 83-116.

${ }^{37}$ Contra Maripil Porteño y otros (2012), Rol 2683-2010, Corte Suprema, casación penal y sentencia de reemplazo.

38 Rol 289-2010, Corte de Apelaciones de Concepción, protección.
} 
ISSN 0719-7160

arbitrariamente y violó la Convención OIT-169. La Corte remarca que es indudable que el proceder de la Municipalidad "ha vulnerado el derecho a la integridad síquica de los recurrentes, por cuanto no cabe duda que la intervención y destrucción de su patrimonio cultural conduce a una sensación de falta de respeto a su identidad social, a sus costumbres y tradiciones, así como a la conservación de las características propias de su etnia, produciendo naturalmente desazón y gran preocupación, que llevan a concluir que se ha conculcado la garantía constitucional consagrada en el Artículo 19 Nr. 1 de la Constitución". ${ }^{39}$

El precedente más importante es Comunidad Indígena Antú Lafquén de Huentetique con Corema de la Región de los Lagos (2012). ${ }^{40}$ En este caso, los recurrentes cuestionaban la aprobación de una simple declaración de impacto ambiental sobre un proyecto de energía eólica, según ellos era necesaria un estudio de impacto ambiental ya que había sitios arqueológicos comprometidos. Además, la consulta indígena no se había realizado en los términos de la Convención OIT-169. La Corte Suprema acogió la protección, ordenó una declaración de impacto ambiental y declaró que la consulta indígena era una etapa adicional en todo procedimiento que involucre a pueblos nativos, según manda la Convención OIT-169. En esta etapa adicional, los indígenas deben tener la posibilidad de influir y moldear el proyecto (no es una simple notificación). ${ }^{41}$ Sólo así el procedimiento ambiental tiene legitimidad. Además de la importancia arqueológica, la Corte destaca que el lugar se realizan rituales religiosos importantes para la etnia. Sin la consulta indígena, el acto administrativo terminal es arbitrario por carecer de motivación.

La sentencia más reciente en esta materia es Toroco con Sociedad inversiones $e$ inmobiliaria Villa Nueva (2013). ${ }^{42}$ Una compañía minera comenzó una prospección minera, sin consulta indígena previa, cerca del Cementerio Indígena Prehispánico de Topáter, el que se utiliza para rituales religiosos. La comunidad indígena argumentó que su derecho a la igualdad y su libertad religiosa estaban siendo vulneradas. La Corte Suprema acogió la acción, y sostuvo que esa actividad prospectiva inconsulta violaba la Convención OIT-169 y afectaba al cementerio; por ende, la igualdad y la libertad religiosa de la comunidad.

\section{Conclusiones}

Los Tribunales chilenos han fallado un número relativamente significativo de casos relacionados con creencias y prácticas ancestrales indígenas. Los fallos aplican directamente tratados como el Pacto Internacional de Derechos Civiles y Políticos (1966) y la Convención OIT169 (1989) en función del Artículo 5 de la Constitución. De esta manera, el derecho internacional de los derechos humanos se integra en forma práctica en el ordenamiento jurídico chileno. En general, se sostiene la igualdad entre creencias y prácticas ancestrales indígenas y las religiones tradicionales mayoritarias. Esto se encuentra en línea con lo sostenido por entes internacionales,

\footnotetext{
${ }^{39}$ Considerando 12.

${ }^{40}$ Rol 10.090-2011, Corte Suprema, protección.

${ }^{41}$ Antes, el mismo criterio fue sostenido por la Corte de Apelaciones de Temuco en Puelman Nanco con COREMA región de la Araucanía (2010), Rol 1705-2009, protección.

42 Rol 3.010/2013, Corte Suprema, protección.
} 
como el Comité de Derechos Humanos de la ONU. Estas decisiones tienen relevancia para la dogmática penal en materia de eximentes de responsabilidad criminal, ya sea en materia de causales de justificación (legítimo ejercicio de un derecho, la libertad religiosa garantizada en la Carta Fundamental) o de eximentes por falta de culpabilidad (error de prohibición). La gran revolución ha sido en el campo de la estructura el procedimiento de evaluación impacto ambiental. Los Tribunales han sostenido que la consulta indígena es una etapa adicional en todo procedimiento que involucre indígenas, en especial la evaluación de impacto ambiental. En este particular procedimiento considera dentro del impacto ambiental la alteración de áreas "con valor antropológico, arqueológico, histórico y, en general, los pertenecientes al patrimonio cultural" (Articulo 11(f) de la Ley 19.300); dentro de estas pueden contarse los lugares sagrados indígenas. Además, dentro de las consecuencias desfavorables a considerar para entrar al sistema se encuentra alteración significativa "de los sistemas de vida y costumbres de grupos humanos", como puede ser la perturbación de rituales religiosos. Algunas prácticas de religiones indígenas pueden generar conflictos que son interesantes de analizar desde la ciencia jurídica y la antropología cultural. 